\title{
Primeiros banquetes dos surdos-mudos no surgimento do esporte silencioso 1834-1924: por uma história política das mobilizações coletivas dos surdos
}

\author{
Des premiers banquets des sourds-muets à l'avènement du \\ sport silencieux 1834-1924: pour une histoire politique des \\ mobilisations collectives des sourds ${ }^{1}$
}

\author{
Andrea BENVENUTO \\ École des Hautes Études en Sciences Sociales (EHESS) \\ Didier SÉGUILLON \\ Université de Paris-Ouest Nanterre La Défense EHESS
}

Tradução: Maria Luizete Sobral Carliez

\begin{abstract}
RÉSUMÉ: Cet article montre l'émergence des premières formes de résistance et d'organisation collective des sourds depuis les premières décennies du XIX ${ }^{\mathrm{e}}$ siècle. Par leur revendication du droit à l'intelligence et à la parole en langue des signes, les sourds ont fait irruption dans l'espace public et politique avec une singularité propre. «Les banquets des sourds-muets» tenus d'abord à Paris depuis 1834 et ensuite dans toute la France, l'avènement du sport silencieux au début du $\mathrm{XX}^{\mathrm{e}}$ siècle ainsi que d'autres lieux et réseaux créés par les sourds au courant du $\mathrm{XIX}^{\mathrm{e}}$ siècle constituent un terrain privilégié d'enquête qui demeure presque entièrement inexploité. Cet article s'appuiera sur les comptes rendus de banquets, des périodiques et des archives associatives, ainsi que sur les rares études contemporaines sur ce thème.
\end{abstract}

MOTS CLÉ : Banquets des sourds-muets. Histoire politique. Mobilisations collectives des sourds. Sourds. Sport silencieux.

RESUMO: Esse artigo mostra o aparecimento das primeiras formas de resistência e organização coletiva dos surdos desde as primeiras décadas do século XIX. Os surdos assumiram firmaram sua posição no âmbito público e político após sua luta pelo direito à afirmação de sua inteligência e à expressão em língua de sinais. Os" banquetes surdos-mudos" realizados inicialmente em Paris desde 1834 e depois em toda a França, o advento do esporte silencioso no início do século XX, bem como outros espaços e conexões criados por surdos ao longo do século XIX constituem um campo privilegiado de investigação que permanece praticamente inexplorado. Esse artigo se apoiará nos registros sobre os banquetes, periódicos e arquivos de associações, bem como nos raros estudos contemporâneos sobre o assunto.

PALAVRAS-CHAVE : Banquetes dos surdos-mudos. História política. Mobilizações coletivas dos surdos. Surdos. Esporte silencioso.

\footnotetext{
${ }^{1}$ Artigo publicado em francês, originalmente na Revista La nouvelle revue de l'adaptation et de la scolarisation 2013/4 ( $\mathrm{N}^{\circ}$ 64)
} 


\section{Introdução}

Bem antes que as mobilizações das pessoas deficientes entrassem na cartografia da ação coletiva no momento da virada do "retorno do ator" (TOURAINE: 1984) e pelas experiências que propiciaram a emergência de novos movimentos sociais (CEFAÏ: 2007) no século $X X$, os surdos já estavam reunidos. Os reagrupamentos cidadãos, artísticos, esportivos e profissionais de surdos começaram a surgir desde as primeiras décadas do século XX: os banquetes dos surdos-mudos, a criação da primeira associação de surdos do mundo, bem como os organismos de imprensa criados pelos surdos para a difusão de seus combates constituem um terreno privilegiado de análise para dar corpo a uma história política das mobilizações coletivas dos surdos, que ainda está para ser escrita. Se a história da educação dos surdos (PRESNEAU: 1980), aquela do lugar que a língua de sinais ocupou nessa educação (CUXAC: 1980; BERNARD, 1999), ou ainda, a das instituições destinadas aos surdos (KARACOSTAS: 1981; BUTON: 1999) na França dos séculos XVIII e XIX têm sido objeto de pesquisas historiográficas específicas ${ }^{2}$, não tem sido assim no que diz respeito ao estudo do movimento dos surdos.

Se as pesquisas sobre a história dos surdos, de sua língua e de sua educação não deixaram de abordar o papel desempenhado pelos próprios surdos, nas primeiras formas de organização em defesa ao seu direito à fala de sinais ${ }^{3}$ como nos seus engajamentos ulteriores na vida da cidade ${ }^{4}$, não se pode dizer o mesmo em relação aos estudos sobre as origens do movimento surdo ao longo do século XIX, sobre as formas de suas sucessivas mobilizações, bem como sobre as razões de seu engajamento, o que não têm

\footnotetext{
${ }^{2}$ A maior parte das teses consagradas aos surdos e à língua de sinais em diversas disciplinas (filosofia, linguística, sociologia, antropologia, ciências da educação etc.), começam por um recorte histórico que remonta, pelo menos, aos séculos em que a educação dos surdos e a língua de sinais se institucionalizou. Nós mencionamos aqui apenas as teses que, por seu caráter pioneiro, se tornaram referencias da historiografia francesa sobre esse assunto. Mencionamos igualmente a primeira tese de doutorado em historia consagrada à história dos surdos do século XIX, Florence Encrevé, Surdos e sociedade francesa no século XIX (1830-1905), Universidade Paris 8, 2008.

${ }^{3}$ Ver: MOTTEZ, Bernard. Les banquets des sourds-muets et la naissance du mouvement sourd. In: L. COUTURIER, L; KARACOSTAS, A. (dir.). Le pouvoir des signes, INJS, Paris, 1989, p. 170-177, retomado em MOTTEZ, Bernard. Les Sourds existent-ils ? Textos reunidos et apresentados por Andrea Benvenuto. L'Harmattan, 2006, p. 340-345. Nós utilizaremos esta versão.

${ }^{4}$ Nós homenageamos Bernard Truffaut, diretor dos Cahiers de l'histoire des sourds, publicados entre 1989 e 1992 pela associação Étienne de Fay, que tornou possível que os documentos de arquivos sobre a imprensa surda, o esporte silencioso, os centros dos surdos, os artistas silenciosos, as histórias de vida, os combates jurídicos e outras temáticas da história surda se tornassem disponíveis.
} 
sido objeto de pesquisas sistemáticas ${ }^{5}$. Reconstituir a história política das mobilizações coletivas dos surdos, da qual este artigo é apenas uma introdução, revelará, além do momento e das condições nas quais os surdos se tornaram verdadeiros atores políticos das mudanças que os envolvem, os antecedentes de uma mobilização pioneira no chamado atualmente Disability Studies, estruturado, entre outros, pela mobilização destes sujeitos. A esse respeito, a história dos surdos e de suas mobilizações merece ser melhor conhecida. Mas a atualidade dessa história política, que só pode ser escrita com a ampliação das pesquisas para todas as áreas das ciências humanas e sociais, reside também na compreensão dos usos da cidadania graças aos quais os surdos reafirmam hoje os seus direitos. Com o movimento de reconhecimento da língua de sinais francesa nos anos 1980 e a legislação que promove a igualdade de oportunidades das pessoas deficientes (lei do dia 11 de fevereiro de 2005), os surdos se mobilizaram para reclamar a presença da língua de sinais francesa como condição de acesso a um pleno exercício de sua cidadania e em pé de igualdade com os ouvintes. Torna-se então relevante revelar elementos de compreensão dos debates políticos atuais dos surdos no quotidiano de sua vida citadina, tais como a rejeição do diagnóstico ultra precoce da surdez ou o questionamento das práticas de implante coclear ${ }^{6}$, para levantar os desafios éticos e políticos sobre esses assuntos.

\title{
2. Nascimento da nação surda e os banquetes dos surdos-mudos no século XIX
}

\author{
É preciso inscrever 1834 entre as grandes datas \\ da história surda. É, com o primeiro banquete \\ que comemora seu nascimento, o início do culto \\ ao abade de l'Épée. É a data de nascimento da \\ nação surda. É o ano em que pela primeira vez \\ os surdos-mudos se outorgaram um tipo de \\ governo. Isso nunca cessou desde então ${ }^{7}$.
}

\footnotetext{
5 Além dos trabalhos de Bernard Truffaut e de Yves Bernard sobre os artistas e a imprensa silenciosa, citamos as duas teses sobre o estudo do movimento surdo: Didier Séguillon (1998), De la gymnastique Amorosienne au sport silencieux: le corps du jeune sourd entre orthopédie et intégration ou l'histoire d'une éducation " à corps et à cri » - 1822-1937, tese de doutorado em ciências e técnicas das atividades físicas e esportivas, Universidade Victor Segalen, Bordeaux II ; Sylvain Kerbourc'h, Le Réveil Sourd d'hier à aujourd'hui (1971-2006) : de l'action collective d'un mouvement culturel pour la réhabilitation de la Langue des signes française, à l'af rmation d'une identité collective pour la participation sociale des sourds, tese em sociologia, EHESS, 2006.

${ }^{6}$ Cf. Stuart Blume, The Arti cial Ear. Cochlear Implants and the Culture of Deafness. New Brunswick, New Jersey and London: Rutgers University Press, 2009.

${ }^{7}$ B. Mottez, «Les banquets de sourds-muets et la naissance du mouvement sourd », op. cit., 1989, p. 340.
} 
É assim que o sociólogo Bernard Mottez inicia o primeiro artigo consagrado às origens do movimento surdo. Dois acontecimentos e uma data: o início do culto ao abade de l'Épée e o nascimento do movimento surdo e 1834. Os dois acontecimentos caminham lado a lado, sua filiação é evidente, mas indireta. $\mathrm{O}$ movimento surdo não começou com o culto ao abade de l'Épée, a nação surda-muda nasceu como reação à ameaça de extinção do ensino das línguas de sinais, iniciado pelo abade no século XVIII, que representava um grande legado dos surdos-mudos, eles instauraram o culto como símbolo de resistência (MOTTEZ, 1989, 345). As línguas de sinais significam um elemento fundamental na existência social e política dos surdos e este culto foi desencadeado na origem do movimento, para frear suas interdições. Estes acontecimentos são o esboço de uma mudança na história da educação dos surdos: eles deixam os bancos da escola e se tornam não somente profissionais de seu próprio ensino, mas também atores políticos (BENVENUTO, 2013).

O propósito aqui não é traçar detalhadamente as etapas da história da educação dos surdos, desde a primeira experiência de ensino coletivo e em língua de sinais instaurado pelo abade de l'Épée em 1760, até o momento do abandono dessa língua no final do século XIX. No entanto, e para melhor compreender o que se passa no momento em que os surdos começam a se organizar para defender sua língua, nós apresentamos uma síntese das grandes transformações de perspectiva no que diz respeito à abordagem da surdez e dos surdos na virada do século. De um ponto de vista filosófico, o ensino dos surdos em língua de sinais instaurado pelo abade de l'Épée, campo epistemológico para a exploração da origem dos conhecimentos, será transformado, ao longo do século XIX, em campo de observação clínica e da otologia, uma nova disciplina que se inicia (BENVENUTO, 2009). Daí em diante e de certo ponto de vista institucional, a obra filantrópica do abade de l'Épée é estruturada sob a tutela dos poderes públicos. Um decreto da Assembleia Nacional do dia 29 de julho de 1791 cria a Instituição Nacional dos Surdos-Mudos de Paris. Sob um ângulo mais pedagógico, a língua de sinais, considerada pelo abade de l'Épée como língua de ensino, perde sua importância nas salas de aula. Ao longo do século XIX e com a "ortopedização da pedagogia" (SÉGUILLON, 1998), a fala articulada como meio para se adquirir certos conhecimentos torna-se um fim em si própria. 
Sob o plano linguístico e cultural, a língua de sinais, considerada até o fim do século XVIII como meio natural de expressão do pensamento, torna-se aos poucos, para a instituição, um obstáculo para a aprendizagem da língua articulada. Para os surdos, a língua de sinais deixa de ser apenas sua língua de ensino e vem a ser o símbolo de sua reinvindicação do direito à inteligência e à cidadania. Por um lado, no decorrer do século XX, a instituição escolar, herdeira da escola do abade de l'Épée é vista como o berço da língua de sinais e da cultura surda (MOTTEZ, 1992) e, por outro, o domínio da invenção técnico-institucional da surdez (BENVENUTO, 2009). Após a morte do abade Sicard, vê-se a intensificação da ofensiva oralista com a separação dos alunos que conseguem falar daqueles que gesticulam, sob o pretexto de evitar o "contágio". O ensino da fala articulada passa a ser realizado somente por profissionais ouvintes, restringindo assim a função dos professores surdos ao posto de repetidores. Para além da questão estritamente pedagógica, a introdução de uma orientação oralista marca um movimento que desencadeia a resistência dos surdos. Em 1834, 122 anos após o nascimento do abade de l'Épée e época do declínio de sua obra, Ferdinand Berthier (1803-1886), professor surdo da Instituição de Paris, juntamente com alguns de seus colegas surdos, como Alphonse Lenoir e Claudius Forestier, resolvem criar um Comitê de surdos-mudos. A primeira decisão desse comitê, na sessão de 15 de novembro de 1834, é a de organizar banquetes anuais para celebrar o nascimento do "pai dos surdosmudos": "esse evento único foi uma grande revolução para o povo surdo-mudo". Não se trata de uma ideia inovadora, mas os banquetes do século XIX, além de reforçarem o laço social é também, inclusive desde a Grécia Antiga, um tipo de atividade política de que dispõem os cidadãos (ROBERT, 2010). Como não havia, durante a monarquia de julho, liberdade para reunião, os protestos se camuflavam nos banquetes. Após 1834, ano em que se realizou o primeiro banquete dos surdos-mudos, as reuniões periódicas das associações ou os encontros de mais de vinte pessoas eram submetidos a uma autorização do governo e sob a tutela da autoridade. E preciso esperar a República, em 1881, para se gozar o direito à liberdade de reunião. Os banquetes dos surdos-mudos, mobilizações contra os riscos que corria a língua de sinais, tinham na verdade uma

\footnotetext{
${ }^{8}$ Banquets des sourds-muets, réunis pour fêter les anniversaires de la naissance de l'abbé de l'Épée ; relação publicada pela Sociedade Central dos Surdos-Mudos de Paris, Jacques Ledoyen Librairie, Paris, 1842 , p. 8.
} 
função eminentemente política e usavam como pretexto a homenagem ao abade. Os banquetes representam um lugar de resistência à dominação da ideologia oralista e consequente criação de um espaço novo dentro da própria comunidade surda (BENVENUTO, 2013).

\section{Funcionamento e organização dos banquetes dos surdos-mudos}

De 1834 a 1838, os banquetes dos surdos-mudos foram organizados pelo Comitê dos Surdos-Mudos e posteriormente pela Sociedade Central dos Surdos-Mudos que, a partir de 1867, tornou-se Sociedade Universal dos Surdos-Mudos (1867-1887) ${ }^{9}$. Essas associações não tinham exclusividade sob os banquetes e, em 1850, a Sociedade Geral de Educação do doutor Blanchet organiza, então, um banquete com duzentos e dezesseis convidados. Por sua vez, o Instituto de Paris também organizou um banquete em 1865 e outro é organizado pela Sociedade de Apoio Fraternal dos Surdos-Mudos em 1880. Os banquetes se diversificam rapidamente e alguns deles são dedicados ao aniversário da criação do Instituto de Surdos. Trata-se dos banquetes de julho (em 1843 e em 1849, retomados de 1862 a 1867, depois em 1883). Essas diversificações no tempo e no espaço institucionais são responsáveis pelas divergências entre os organizadores e as associações rivais. A presença de mulheres está dentre essas divergências. Até 1891, os banquetes organizados pela Sociedade Central, mais tarde Sociedade Universal, aceitavam apenas homens, mesmo após a morte de Ferdinand Berthier em 1886, ferrenho opositor à presença de mulheres. As mulheres vão ao seu primeiro banquete em 23 de novembro de 1886, a convite da Sociedade de Apoio fraternal dos SurdosMudos, criada neste mesmo ano. Sobre os convidados, somente "os amigos dos SurdosMudos serão admitidos no banquete", aqueles apresentados por um membro do comitê ou por subscrição. No domingo de 30 de novembro de 1834, "às cinco horas, aproximadamente sessenta membros desta singular nação reuniram-se nos salões do

\footnotetext{
${ }^{9}$ Além dos relatórios já citados e publicados pela Sociedade Central dos Surdos-Mudos de Paris nos fundamentamos em outras fontes: Registres des Procès Verbaux des réunions annuelles des Sourdsmuets, $1^{\mathrm{er}}$ vol. (1834-1865) et $2^{\mathrm{e}} \mathrm{vol}$. (1866-1907), manuscritos; Aperçu historique des Banquets annuels des Sourds-Muets en l'honneur de la naissance de l'abbé de l'Épée, publicado graças ao Comité assinante de 1906 sob os auspícios da Sociedade de Apoio Fraternal dos Surdos-Mudos da França, abrill, 1913 ; como, em 1869, encerrou-se a publicação dos registros dos banquetes, os dados posteriores foram publicados na imprensa surda, como por exemplo o Bulletin de la Société Universelle des Sourds-Muets (relatórios dos banquetes de 1869-1870, l'Abbé de l'Épée. Le Journal des Sourds-muets (banquets de 1888-1889), Le Réveil des Sourds-Muets (banquets de 1900).
} 
restaurante Veau qui tête, na praça do Châtelet ${ }^{10}$ ". Havia outros restaurantes como o salão Ladmiral no faubourg Saint-Germain, ("para muitos a gastronomia era o critério que contava nessa decisão... Nesse caso, a lei dos pobres prevalecia e os surdos-mudos se submetiam", registro do $4^{\circ}$ banquete, dia 3 de dezembro de 1837); o salão do Sr. Auger no Cassino Saint-Martin; restaurante Notta, Boulevard Poissonnière; o restaurante Pierron; via dos Martyrs; o restaurante Carré, avenida de Clichy. Inicialmente, os banquetes eram somente um jantar precedido de brindes em memória ao abade de l'Épée e a diferentes pessoas. Depois, introduziram a missa, o baile e diversos espetáculos que prolongavam as festividades durante o dia todo. A disposição das mesas do banquete obedecia a um código estrito, à direita e à esquerda do presidente se posicionavam os convidados de honra, falantes (ouvintes) e surdos-mudos. A mesa em frente era reservada aos surdos e seus lugares eram enumerados e sorteados. O número dos convidados presentes variava, de trinta até mais de cem pessoas, de acordo com o ano em função da vitalidade das associações organizadoras e dos conflitos internos. Os registros manuscritos dos processos verbais dos banquetes dos surdos$\operatorname{mudos}^{11}$ nos permitem verificar a quantidade de pessoas mas também sua origem profissional e onde moravam. Os participantes vinham de Paris, do interior da França ou do estrangeiro, eles eram operários, artesãos, professores, pintores, gravadores, empregados, impressores, diretores de escola, supervisores mestres, mestres de estudos, carpinteiros, alunos, estofadores, antigos empregados administrativos, desenhistas litográficos, sapateiros, oculistas, estofadores de automóveis, joalheiros, tipógrafos, monitores, artesãos de marfim, alfaiates. Alguns convidados de honra acompanhavam os surdos ou declinavam do convite em cartas que eram lidas para dar mais visibilidade a essas manifestações: Chateaubriand, Victor Hugo, Victor Considérant, Benjamin Constant, Alphonse de Lamartine, o Conde Eugène de Ségur, Pierre-Jean de Béranger, o Barão de Gérando, Eugène Garay de Monglave, Ledru-Rollin, Laurent de Jussieu, Jules Ferry, dentre outros. O comitê, formado por surdos e alguns amigos ouvintes, decidia tudo, os participantes, seus objetivos, as condições de acesso, a língua usada. Banquetes significavam comer e eles não existiam somente em Paris, as associações

\footnotetext{
${ }^{10}$ Banquets des sourds-muets, op.cit., tome I, p. 5.

${ }^{11}$ Registres des Procès Verbaux des réunions annuelles des Sourds-muets, $1 \mathrm{er}^{\mathrm{vol}}$ (1834-1865) et $2^{\mathrm{e}}$ vol. (1866-1907), manuscritos.
} 
regionais se apropriaram desta prática e os banquetes foram também organizados no interior do País.

Os intérpretes tornavam os discursos acessíveis aos ouvintes que não dominavam a língua de sinais. Lê-se no relatório do banquete de 1835: "Discurso em mímica, Berthier entrega o manuscrito à Monglave que faz a leitura para os falantes da reunião". Em 1836: "Serph Dumagnou (um dos nossos amigos mais honrados, antigo procurador do rei) leu a resposta de Béranger e logo após traduziu por meio de mímica a resposta de Bouilly brindando em sua honra por Berthier." 1837: "leitura da resposta de Lamartine por Eugênio de Monglave, o leitor habitual dos surdos-mudos.”, o que é atualmente o intérprete de língua de sinais. O conteúdo dos pronunciamentos nos banquetes dos surdos-mudos na "única língua permitida [...] a mímica", a língua de sinais, é relatado pela Sociedade Central dos Surdos-Mudos de Paris: Banquetes dos surdos-mudos, reunidos para festejar o nascimento do abade de l'Épée (tomo I, banquetes de 1834-1848; tomo II, banquetes de 1849-1862 e tomo III, banquetes de 1864-1869). A imprensa foi, também, um importante vetor de informação na difusão desses eventos e um instrumento político poderoso que manteve os surdos atentos. Lêse, por exemplo, nos relatórios dos banquetes na imprensa surda: Boletim da Sociedade Universal dos Surdos-Mudos (banquetes de 1888-1889); Abade de l'Épée; Le Réveil des Sourds-Muets (banquetes de 1900). Foram publicados registros sobre o primeiro banquete em jornais da época como Le Temps, La Chronique de Paris, Le Courrier français, Le National, Le Journal des débats, La Quotidienne, La Gazette de France, La Tribune, Le Moniteur universel, Le Corsaire, Le Cabinet de lecture, Le Journal de Paris, L'Impartial.

\section{Uma história política de reconfiguração igualitária}

Os banquetes dos surdos-mudos do século XIX se constituíram no espaço que fez emergir a "nação surda", para usar aqui o vocabulário daquela época. O importante nesse contexto, além da sua história de mobilização, é a diversidade de organização que os surdos assimilaram para se impor no espaço público e redefinir seus lugares. Sob esse aspecto, a nação surda deve ser compreendida em termos de filiação. Uma nação fraternal acima de tudo: são "amigos", "companheiros de infortúnio", o que significa uma nação que reúne os que partilham destino e objetivos comuns. Trata-se de uma 
filiação intelectual em que o direito à inteligência e à emancipação intelectual reúnem os espíritos surdos e os amigos ouvintes. É também uma filiação simbólica: a nação se reúne para homenagear o abade de l'Épée, “pai espiritual dos surdos-mudos”, em reconhecimento de sua obra. Mas os surdos consideram que "o abade de l'Épée inventou a língua de sinais assim como Cristóvão Colombo descobriu a América. Ambos revelaram o que se encontrava perdido, esquecido há séculos [...]" (registro do primeiro banquete). Enfim, a filiação é política: a nação surda não se inscreve por completo sob uma ótica de regeneração que é própria à mentalidade do Século das Luzes. Trata-se então para os surdos, que se consideram seres inteligentes e que falam, experimentar o jamais visto. A obra do abade vem, nessa perspectiva, torná-los visíveis. O que nos releva segundo uma leitura política dessa nação é que, mais do que a defesa da língua de sinais, é o direito à igualdade, a luta primordial deles. Pois se o direito à cidadania contribuiu para que as crianças surdas fossem educadas, o que lhes dá o status de sujeitos políticos é o direito à cidadania. Os surdos são então responsáveis por uma subversão da ordem no que diz respeito às pessoas falantes: os intérpretes presentes nos banquetes estavam ali para tornar a informação acessível aos ouvintes, uma verdadeira inversão de paradigma. A língua de sinais não pode então ser considerada uma prótese para resolver uma deficiência restrita ao surdo, mas uma língua como outra qualquer e indispensável às interações entre surdos e ouvintes. É um modo de ver e dizer comum a todos os seus integrantes e que define a nação surda como tal e não a ideia de que a surdez fisiológica se constituiria como critério de pertencimento a ela, o que reforçaria um suposto isolamento dos surdos. Enfim, a nação surda se delineia numa política em que suas inteligências, seus esforços e suas ideias iluministas são comuns a todos e cuja força coletiva está a seu serviço. Uma vez o movimento iniciado, a nação surda constitui o terreno fecundo de uma atividade que se diversificará para outros campos da vida dos surdos, para além dos muros das instituições educativas. E assim é com a imprensa, os congressos, as moradias, as associações solidárias, os artistas silenciosos, ou seja, lugares e redes que contribuíram para a expansão do movimento. Que formas tomou posteriormente esse movimento? 


\section{Espaços e conexões de construção do movimento surdo: imprensa, congressos, moradias, associações solidárias e artistas silenciosos}

Ferdinand Berthier era consciente de que um domínio como esse dos espaços públicos só poderia se concretizar com a busca de meios suficientes para que essa voz tivesse eco na comunidade surda. Ao declarar, em 1835, como ressaltamos acima, "é a ela (imprensa) que nós nos dirigiremos se uns idiotas continuarem a tentar nos destruir negando que a igualdade de inteligência nos dá direitos iguais na grande família dos homens", Berthier profetiza o que se tornará um dos argumentos dos surdos para afrontar os questionamentos sobre o uso da língua de sinais nos ambientes públicos. Já por volta de 1870 verifica-se um verdadeiro desenvolvimento da imprensa silenciosa (TRUFFAUT: 1990), ou melhor, a imprensa feita para e pelos surdos. A maioria dos jornais reservam relevante espaço para a reflexão sobre a educação das crianças surdas, opondo-se de forma às vezes radical ao método do oralismo puro ${ }^{12}$. A maior parte dos jornais reserva um espaço importante para a reflexão sobre a educação das crianças surdas e se opõe, às vezes de maneira radical, ao método oral puro ${ }^{13}$. Somente em 1890, com o lançamento do La Gazette du sourd-muet, surge o primeiro jornal de massa dos surdos, tanto pela importância de sua difusão quanto por sua relativa estabilidade (TRUFFAUT, 1990). O primeiro jornal de massa dos surdos terá que esperar 1890 para ver a luz do dia, com o lançamento de La Gazette du sourd-muet, cuja importância de difusão se equipara a sua relativa estabilidade (TRUFFAUT: 1990). Em 1916, após a

\footnotetext{
${ }^{12}$ Além de informativa essa imprensa era também de cunho militante e polêmico. A primeira publicação de surdos data de 1870, com o Bulletin de la Société universelle des sourds-muets, órgão da associação fundada em 1838 por Ferdinand Berthier denominada Sociedade Central dos surdos-mudos. Dirigida à época por Benjamin Dubois, professor em Paris et secretário geral da Sociedade Universal, esse jornal tinha colaboradores como ex-professores do Instituto, dente eles ressalta-se Berthier, Forestier et Lenoir. Antes de 190, alguns periódicos são publicados por pessoas surdas: Bulletin de la société Universelle (Diretor B. Dubois, 1870- ?) ; La Défense du Sourd-Muet (directeur J. Turcan, 1884-1886) ; Le Courrier des Sourds-Muets (Diretor J. Turcan, 1887-1888) ; La Sincérité (Diretor L. Rémond, 1887- ?) ; L'abbé de l'Épée (Diretor B. Dubois, 1888-1889) ; L'Écho de la Société d'Appui Fraternel des Sourds-Muets (Diretor J. Cochefer, 1888-1890) ; La Gazette des Sourds-Muets (diretor H. Rémy, 1890-1895) ; La France silencieuse (Directeur R. Desperriers, 1894) ; Le Journal des Sourds-Muets (Diretor H. Gaillard, 1894-1906) ; L'Avenir des Sourds-Muets (Diretor P. Villanova, 1894-1895) ; Le Sourd-Muet Illustré (Diretor J. Berthet, 1897- ?) ; La Silencieuse (Diretor H. Gaillard, 1898) ; La République de demain (Diretor H. Gaillard, 1899-1900) ; Le Pilori Silencieux (Diretor : ?, 1898); La Revue Pédagogique de l'Enseignement des Sourds-Muets (Diretor H. Gaillard, 1899-1900).

${ }^{13} \mathrm{O}$ jornal La Défense des sourds-muets nasce em dezembro de 1884, título bastante significativo e cujo responsável é Joseph Turcan. Em primeiro de janeiro de 1887, esse jornal passa a chamar-se Le Courrier français des sourds-muets e, em 1902, Joseph Turcan publica La France des sourds- muets. Em 1887, surge o primeiro número da Sincérité, um jornal de opinião. Em seguida o L'abbé de l'Épée é publicado em março de 1888 e L'Écho de la société d'appui fraternel des sourds-muets de France também. Essa última publicação é órgão de uma associação que cria um sistema de aposentadoria para os surdos.
} 
morte do seu fundador, esse jornal se afirma em Paris e sua publicação irá até 1961, quando passa a se chamar La voix du Sourd. Dentre muitos redatores que se sucederam à frente dessa publicação, Eugène Rubens-Alcais tem papel preponderante no surgimento e posterior reconhecimento do esporte silencioso.

A imprensa silenciosa, herdeira de um ensino em que o francês escrito tem importante lugar (Séguillon, 2002a), perde sua força progressivamente com a dominação do oralismo no final do século XIX. Os militantes veteranos envelhecem e a nova geração não levanta a mesma bandeira que, com o congresso de Milão em 1880, tem novo leme "Viva a fala". A ideologia oralista não pregava apenas a imposição da língua oral às crianças surdas, mas excluía os surdos da apropriação dos bens culturais, dos meios de expressão e de comunicação de suas ideias através da imprensa escrita em espaço público. Em dez anos ou mais, submetidos a uma escolaridade voltada para as técnicas de correção da fala e focada na oralização, os surdos jovens deixavam as escolas praticamente analfabetos. Isso trouxe consequências à imprensa silenciosa assim como à apropriação da escrita da história dos surdos por eles mesmos ${ }^{14}$.

Uma outra forma de ação coletiva dos surdos foi a realização de congressos (BERNARD, 2001), que são verdadeiros espaços de transmissão e de criação de redes nacionais e internacionais, onde além de se analisar a política educativa aplicada nas escolas de crianças surdas, servem também para revelar e denunciar o progressivo retrocesso linguístico e profissional oriundos da dominação da ideologia oralista. Esses congressos são organizados pelos surdos e para eles. Em 1889, o primeiro é organizado em Paris, pelos surdos franceses, o segundo em Chicago em 1893 e o terceiro novamente em Paris, no ano de 1900. Inúmeras reivindicações foram formuladas. Henri Gaillard chama sua comunicação, em Chicago, de "O Surdo-Mudo militando na França" ou "Sobre a situação do ensino dos Surdos-mudos" ou ainda "Panorama sobre a evolução do Mundo Surdo-Mudo contemporâneo”. G. Chambellan, antigo professor das instituições nacionais de Bordeaux e Paris, apresenta, também em Chicago, uma comunicação "em mímica", interpretada por René Desperriers sobre "O método oral segundo a experiência prática". Podemos ressaltar a atualidade desses temas: direito à diferença, respeito ao uso da língua de sinais, direito ao trabalho. O Congresso de Paris

\footnotetext{
${ }^{14}$ Dois dentre os artistas publicados neste dossiê levanta, precisamente, essa questão.
} 
de 1889, com o objetivo de discutir questões sobre assistência e educação dos surdosmudos, levanta a bandeira: "os sinais gestuais não desaparecerão nunca". Esses congressos, verdadeiros espaços de encontro e construção de conexões dos surdos em nível nacional, marcam uma etapa decisiva do movimento surdo pela sua dimensão em escala internacional.

Um dia após o Congresso de Milão em 1880, Joseph Cochefer ${ }^{15}$ funda a Sociedade de apoio fraternal aos surdos-mudos da França e, rapidamente, nascem outras associações no interior do País: Associação dos amigos dos surdos-mudos da Champagne, Associação fraternal dos surdos-mudos da Normandia. Duas federações são institucionalizadas para gerir essas associações: a Federação das sociedades de surdos-mudos, fundada em 1896 por Joseph Cochefer e alguns anos mais tarde a União nacional das Sociedades de Auxílio Mútuo aos surdos-mudos. Ao cabo de violentas lutas internas entre essas duas associações, surge um grupo representativo do movimento surdo francês que resguarda e defende os direitos dos surdos. Essa organização se transforma num espaço de defesa da língua de sinais e da comunidade surda em geral. Veem-se, nessa época, artistas surdos expondo e ganhando vários prêmios em diferentes salões, inclusive na exposição universal de 1889. Dentre outros artistas estão Paul Choppin ${ }^{16}$ que estudou no atelier de Felguire e Jouffroy, Plessis ${ }^{17}$ e foi aluno de Barrias e de Princeteau ${ }^{18}$. Os surdos expõem em grandes salões e além do sucesso, obtêm medalhas. Estes surdos artistas são reconhecidos e aclamados como a elite da comunidade surda nos banquetes, onde eles se afirmam tanto como artistas e como surdos no mundo dos artistas (BERNARD: 1999). Ao final do século XIX e início do século XX, os artistas surdos expõem na Exposição universal de 1889 e de

15 Antoine Joseph Cochefer (1849- 1923). No final de sua escolaridade, ele entra para a escola de Belas ArtesÀ la fin de sa scolarité no atelier Dumont. Escultor de formação, oficial da academia e condecorado da Sociedade de apoio às ações para bem. Éle é um dos grandes expoentes do movimento surdo do final do século XIX e início do XX, também autor de um painel decorativo sobre a Emancipação dos surdos-mudos.

16 Paul Choppin (1886-1937). Artista Escultor. Surdo aos dois anos, estudou em Paris. Sua formação artistica é feita na Escola das Artes decorativas e depois na Escola nacional de Belas Artes, ressaltamos sua obra Le vainqueur de la Bastille.

17 Félix Plessis (1869 - 1917). Artista escultor, sua importante obra Cavalier du $1^{\text {er }}$ Empire.

18 René Pierre Charles Princeteau (1843-1914). Artista plástico, René Princeteau vem de uma família da alta burguesia originária de Bordeaux. Henri de Toulouse-Lautrec frequenta seu ateliê logo no início dos anos 1880. Ressaltamos suas obras Les chevaux effrayés par le train (vers 1870/1875), Le retour de la chasse (aproximadamente 1890/1895). 
1912. Ao envelhecerem, esse brilho se apaga por si próprio. Essa experiência dos artistas surdos é particularmente rica de ensinos, um exemplo de como se pode construir uma forma de mobilização essencialmente edificante. Durante muito tempo, eles foram considerados como artistas surdos no seio da comunidade artística francesa e receberam, como seus semelhantes ouvintes, títulos, medalhas e recompensas. Suas obras eram vendidas e obtiveram reconhecimento, apesar de ainda reivindicarem uma identidade surda, como é o caso dos que participam do atual movimento artístico surdo $^{19}$. A mobilização daquela época só foi possível, porque esses surdos conseguiram destacar suas competências visuais e gestuais, o que de certa forma representa uma extensão do trabalho do abade de l'Epée.

A língua de sinais banida das salas de aula persistiu nos lugares onde os surdos se juntavam para viver seu quotidiano. Assiste-se assim à emergência de uma outra atividade, destinada ao lazer, que se tornará o novo porta-bandeira do movimento surdo na primeira metade do século XX: o movimento esportivo silencioso.

\section{Um movimento único e internacional: o esporte silencioso}

Ao final do século XIX, os surdos ampliaram essa mobilização coletiva, praticando atividades esportivas e se tornaram, para além de simples participação de uma ginástica paramilitar, praticantes de esportes associativos, modernos e autogeridos (ULMANN, 1982). Nessa época, o ciclismo era a prática esportiva central na França (ARNAUD \& CAMY, 1986) e os surdos se apropriaram dessa atividade, iniciando a prática da bicicleta no seio das associações esportivas dos ouvintes e depois nas sociedades surdas. A exemplo do movimento esportivo dos ouvintes, o ciclismo passa a ser a essência da construção do movimento esportivo silencioso, o que nos é mostrado por elementos da história dessa prática esportiva. Por exemplo, a corrida de cem quilômetros do trajeto Epenay-Mézières, organizada pela União velocipédica de Epenay conta, pela primeira vez, com a participação de cinco jovens surdos e Henri Mercier ${ }^{20}$ é o primeiro colocado entre sessenta participantes surdos e ouvintes. Em 1894, alguns surdos eram observados por curiosos nas estradas da Europa. De fato, Jaroslar Barta,

\footnotetext{
19 Sobre esse assunto ver o artigo de Olivier Schetrit nesse dossier.

20 Henri Mercier. Neto de Eugène Mercier, fundador das campanhas Mercier e foi aluno do 'I.N.J.S. de Paris, esportivo e brilhante ciclista e irmão de Emile Mercier, Presidente-fundador da Associação dos Amigos dos surdos da Champagne e presidentes do círculo Abade de l'Epée em Reims.
} 
um surdo tcheco, vindo da Alemanha e da Bélgica, passa por Paris antes de ir em direção da Espanha, da Itália e da Áustria. Nesse mesmo ano, outro surdo esportivo chamado Danner participa da corrida de 50 quilômetros no trajeto Choisy-le-RoiVersailles. São organizadas inúmeras corridas como a que foi feita no dia 23 de dezembro de 1894 entre ciclistas surdos e um carro atrelado, dia em que uma delegação de surdos parisienses iria a Versailles para uma cerimônia de homenagem diante da estátua do abade de l'Epée. Henri Mercier participou da corrida de 100 quilômetros em Epernay e chegou em quarto colocado, em 3 horas e 40 minutos. Entretanto a prática desse esporte deixa de ser algo atrelado a iniciativas individuais e, em reunião, os surdos decidem criar o primeiro campeonato oficioso do ciclismo no dia 30 de junho de 1895, em Sy-le-Roi-Versailles. Trata-se de uma corrida de cinquenta quilômetros entre Paris e La Varenne-Chènnevières, reunindo doze concorrentes. É Mercier, ele novamente é o primeiro colocado, com um percurso feito em uma hora e trinta e oito minutos, sem falar nas peripécias causadas pelos erros de sinalização, pela ausência de supervisores da corrida dentre outros. A presença de Henri Mercier não é um acaso e basta lembrar que ao final do século XIX, a bicicleta ainda é considerada objeto de "luxo". A bicicleta, objeto caro, torna-se dali em diante e rapidamente um objeto de consumo, mas ainda pouco presente entre os menos afortunados. É então natural que os surdos abastados viessem a ser os pioneiros do esporte silencioso. Desde o início do século $\mathrm{XX}$, a relativa democratização da bicicleta abre possibilidades para a difusão dessa prática esportiva dirigida a toda a população francesa e particularmente à população surda.

Essas primeiras práticas esportivas dos surdos constituem autênticos espaços de mobilizações coletivas, que se desenvolvem e se diversificam primeiramente no seio das associações de ouvintes como é o caso da União velocipédica de Epernay e, posteriormente nas associações dos próprios surdos, é o caso do Club cycliste des sourds-muets fundado em 1899. A sede dessa primeira sociedade esportiva silenciosa funciona em Paris, no Café de la Jeune France; no boulevard Saint Michel ${ }^{21}$ e seu fundador, Desperriers, é também tesoureiro da Associação dos amigos do Sena e zonas limítrofes. Essas associações têm vínculos estreitos. De fato, a Associação dos Amigos do Sena e Zonas Limítrofes:

$21 \quad$ Revue générale de l'enseignement des sourds-muets (1899). 
Apoia moralmente cada um de seus membros e, se necessário, por meio de pecúlio, no que diz respeito a processos em caso de acidente de trabalho, mas o ciclista a quem o apoio é destinado deve em dia com seus pagamentos e estar em seu pleno direito ${ }^{22}$.

No domingo do dia 12 de março desse mesmo ano, organizou-se a primeira largada, da Porte Dorée em Paris para Conflans-Sainte-Honorine e no final do dia corredores e torcedores se encontraram no restaurante. Em 21 de abril, a prefeitura do Sena aprova a criação desse primeiro clube esportivo silencioso e a mídia silenciosa felicita o acontecimento, reforçando a consagração oficial da inserção dos surdos-mudos no movimento esportivo mundial. Um vasto programa com atividades durante todo o mês de julho é oferecido ao público, já anunciando o grande vigor do clube. Em agosto desse mesmo ano, os surdos da região do Centro da França organizam por sua vez uma grande reunião em Cusset-Vichy da qual fazem parte numerosos ciclistas parisienses, inclusive Henry Mercier chegado de Epernay. Após a corrida, tanto os ciclistas como os simples observadores participam do banquete anual dos surdos-mudos.

Considerado uma nova forma de mobilização, o esporte silencioso surge logo no início do século XX como espaço novo de expressão construída pelos surdos e para eles próprios, onde também se encontram, interagem em língua de sinais e iniciam os jovens nessa língua, uma estratégia privilegiada para sua preservação e uso. A organização associativa do esporte silencioso torna-se lugar de excelência para as interações entre os surdos e sua coesão social, para além das instituições educativas. Desde então, o esporte silencioso passa a se integrar ao modo de vida coletiva dos surdos e é um elemento fundador do movimento silencioso durante a primeira metade do século XX, alheio às grandes escolas dos jovens surdos (SEGUILLON, 2013). Em 1924, Eugène RubensAlcais conclui no editorial do Sportsman Silencieux que "nesses primeiros Jogos internacionais silenciosos, os esportistas silenciosos obtiveram sucessos dignos de uma grande nação que somos" ${ }^{״ 2}$. Isso nos remete à ideia exposta primeiramente por Pierre Desloges no século XVIII: os surdos se reúnem, comunicam-se entre eles em língua de sinais e formam uma comunidade. E é graças aos banquetes dos surdos-mudos do século XIX que a noção de povo ou de nação reafirma a dimensão comunitária com

\footnotetext{
22 Atos do Congresso internacional sobre o Estudo das Questões de Assistência e Educação dos Surdos-Mudos, da Exposição Universal, ocorrida em Paris, nos dias 6, 7 e 8 de agosto de 1900.

23 A redação. «Resultados dos Jogos internacionais silenciosos de Paris 10-17 agosto de 1924 », Sportsman silencieux, $\mathrm{n}^{\circ} 67$, setembro de 1924.
} 
formas de organização e institucionalização próprias. Os congressos dos surdos e o esporte silencioso contribuem para a dimensão internacional já atestada desde os primeiros banquetes dos surdos-mudos em que os convidados estrangeiros ocupavam lugar de honra.

A vida comunitária em torno das associações foi assim reforçada e, a exemplo dos esportivos ouvintes, os surdos criaram uma imprensa esportiva surda e adquiriram estruturas associativas nacionais e internacionais. O objetivo foi sempre se reunir, mas também o garantir um lugar de igualdade de condições em relação aos ouvintes. $\mathrm{O}$ redator do Sportsman silencieux se pronuncia de forma bastante clara sobre o assunto:

Os surdos-mudos permanecerão sempre isolados no meio da massa ouvinte sem que uma individualidade silenciosa possa jamais se equiparar ao renome de um Capentier, um Friol, um Bouin. No meio dos surdos-mudos de todos os países, os campeonatos têm a mesma consagração que os dos ouvintes ${ }^{24}$

Essa falta de reconhecimento suscita nos surdos a extrema necessidade de mostrar sua capacidade e de se organizarem de forma coletiva, criando espaços de encontros nacionais e internacionais.

\section{Conclusão}

O movimento dos surdos nasce no século XIX com a criação da primeira associação de surdos e a implementação dos banquetes dos surdos-mudos. Os banquetes inauguram uma etapa política capital na construção do movimento e marcaram o momento em que a língua de sinais abre a possibilidade aos surdos de ocuparem uma outra posição, sem se limitarem apenas a sujeitos a serem instruídos, até então considerados incapazes, e mostram outras capacidades. A institucionalização do movimento silencioso com as associações, seus salões artísticos, sua imprensa e seu esporte silencioso expressaram a quantidade de iniciativas por meio das quais os surdos manifestaram sua existência e demonstraram sua igualdade. A história política das mobilizações dos surdos mostra como os surdos tomaram seu destino nas próprias mãos de forma coletiva; e não uma situação em que o reconhecimento social dos surdos e sua liberdade de expressão teria sido algo autorizado por poderes públicos, educativos ou

24 A redação « Uma Federação internacional esportiva dos surdos-mudos, o Sportsman silencieux, $\mathrm{n}^{\circ} 16$, abril / maio de 1920 . 
outros. A reivindicação do direito à língua de sinais permitiu que os surdos pudessem intervir no campo político e tivessem voz ativa em espaços públicos, um ato de emancipação por excelência que desestabiliza o regime de desigualdade.

Se insistimos em reivindicar o caráter político da história das mobilizações coletivas dos surdos, a questão, parafraseando Jacques Rancière (1987: 79), não está em provar que a inteligência dos surdos é igual a dos ouvintes, mas ver o que eles conseguiram fazer partindo dessa suposição.

\section{Referências}

Actes du Congrès international pour l'étude des questions d'assistance et d'éducation des Sourds-Muets, de 1'exposition universelle, tenu à Paris les 6, 7 et 8 août 1900.

ARNAUD (P.) et CAmy (J.), La naissance du mouvement sportif associatif en France. Sociabilité et formes de pratiques sportives, Presses universitaires de Lyon, Lyon, 1986.

Aperçu historique des banquets annuels des Sourds-Muets en l'honneur de la naissance de l'abbé de l'Épée, publié par les soins du comité souscripteur de 1906 sous les auspice de la Société d'appui Fraternelf des Sourds-Muets de France, avril 1913.

Banquets des sourds-muets, réunis pour fêter les anniversaires de la naissance de l'abbé de l'Épée, Relation publiée par la Société centrale des Sourds-Muets de Paris, Tome 1, chez Jacques Ledoyen, Libraire, Paris, 1842.

Banquets des sourds-muets, réunis pour fêter les anniversaires de la naissance de l'abbé de l'Épée, Relation publiée par la Société centrale des Sourds-Muets de Paris, Tome 2, chez Jacques Ledoyen, Libraire, Paris, 1864.

Banquets des sourds-muets, réunis pour fêter les anniversaires de la naissance de l'abbé de l'Épée, Relation publiée par la Société universelle des Sourds-Muets, Tome 3, Typographie Arbieu, Lejay et Cie, Poissy, 1870.

BENVENUTO, A. Qu'est-ce qu'un sourd ? De la gure au sujet philosophique, Thèse de doctorat en philosophie, Université Paris 8, 2009.

Les banquets des sourds-muets au $\mathrm{xix}^{\mathrm{e}}$ siècle et la naissance du mouvement sourd, La Revue des Livres, n 10, mars, avril 2013.

BERNARD, Y. Approche de la gestualité à l'institution des sourds-muets de Paris au $x$ iiii $^{\mathbf{e}}$ et au $x^{\mathbf{e}} \mathbf{e}^{\mathbf{e}}$ siècle, thèse de doctorat en linguistique, Université Paris V RenéDescartes, 1999. 
BERNARD, Y. Les Congrès de sourds-muets après Milan : Paris 1889, Chicago 1893, Paris 1900, Retour sur le Congrès de Milan, Revue Surdité, nº 4, 2001.

BLUME, S. The Arti cial Ear. Cochlear Implants and the Culture of Deafness, Rutgers University Press, New Jersey and London, New Brunswick, 2009.

BUTON, F. Les corps saisis par l'État. L'éducation des sourds-muets et des aveugles au xix ${ }^{\mathbf{e}}$ siècle. Contribution à la sociohistoire de l'État (1789-1885), thèse de doctorat en sociologie politique, EHESS, 1999.

CEFAÏ, D. Pourquoi se mobilise-t-on ? Les théories de l'action collective, La Découverte, Paris, 2007.

CUXAC, C. L'Éducation des sourds en France depuis l'abbé de l'Épée. Aperçu linguistique et historique sur la langue des signes française, thèse de doctorat en linguistique, Université Paris V René Descartes, 1980.

ENCREVÉ, F. Sourds et société française au xix $\mathbf{e}^{\mathbf{e}}$ siècle (1830-1905), thèse de doctorat en histoire, Université Paris 8, 2008.

KarACoStAS, A. L'institution nationale des sourds-muets de Paris de 1790 à 1800. Histoire d'un corps à corps, thèse de doctorat en médecine, Université Paris V René Descartes, 1981.

KERBOURC'H, S. Le Réveil Sourd d'hier à aujourd'hui (1971-2006) : de l'action collective d'un mouvement culturel pour la réhabilitation de la Langue des signes française, à l'af rmation d'une identité collective pour la participation sociale des sourds, thèse de sociologie, EHESS, 2006.

MOTTEZ, M. Les banquets des sourds-muets et la naissance du mouvement sourd », 1989 in Bernard mottez, Les Sourds existent-ils? Textes réunis et présentés par Andrea Benvenuto, L'Harmattan, 2006.

MOTTEZ, B. Savoirs, savoir-faire et façons d'être. La transmission chez les Sourds, Les Sourds existent-ils ?, 1992, Textes réunis et présentés par Andrea Benvenuto, Éditions L'Harmattan, 2006.

MOTTEZ, B. Les Sourds existent-ils ? Textes réunis et présentés par Andrea Benvenuto, Éditions L’Harmattan, 2006.

PRESNEAU, J.-R. L'idée de surdité et l'éducation des enfants sourds du $\mathbf{x v i}^{\mathbf{e}}$ au $\mathbf{x v i i i}^{\mathbf{e}}$ siècle, thèse de doctorat en sciences sociales, EHESS, 1980.

RANCIÈRE (J.), Le maître ignorant. Cinq leçons sur l'émancipation intellectuelle, Fayard, Paris, 1987.

ROBERT (V.), Le temps des banquets. Politique et symbolique d'une génération (18181848), Publications de la Sorbonne, 2010. 
RUBENS-ALCAIS (E.), «Une Fédération internationale sportive des sourds-muets », Journal Sportsman silencieux, $\mathrm{n}^{\circ} 16$, avril-mai 1920.

RUBENS-ALCAIS (E.), « Résultats des Jeux internationaux silencieux à Paris 10- 17 août 1924 », Journal Sportsman silencieux, n 67, septembre 1924.

SÉGUILLON (D.), De la gymnastique Amorosienne au sport silencieux : le corps du jeune sourd entre orthopédie et intégration ou l'histoire d'une éducation " à corps et à cri »-1822-1937, thèse de doctorat en sciences et techniques des activités physiques et sportives, Université Victor Segalen, Bordeaux II, 1998.

SÉGUILLON (D.), « Du langage des signes à l'apprentissage de la parole ou l'échec d'une conception », Revue Staps, 2002a.

SÉGUILLON (D.), "The Origins and Consequences of the First World Games for the Deaf, 1924“, The International Journal of History of Sport, 2002b.

SÉGUILLON (D.), «L'inclusion des Sourds sportifs au sein du mouvement handisport : un dé impossible ? », Sébastien Ruf é et Sylvain Ferez Corps (sous la direction de), Sport Handicaps, tome I. L'institutionnalisation du mouvement handisport (19542008), Éditions Téraèdre, 2013.

TOURAINE (A.), Le Retour de l'acteur, Fayard, Paris, 1984. truffAut (B.), «La presse des sourds avant $1900 »$, Les Cahiers de l'histoire

des sourds, $\mathrm{n}^{\circ} 4,1990$.

ULMANN (J.), De la gymnastique aux sports modernes. Histoire des doctrines de l'éducation physique, Second tirage. L'histoire des sciences: textes et études, Vrin, Paris, 1982. 